\title{
Endophytic fungi from the Amazonian plant Paullinia cupana and from Olea europaea isolated using cassava as an alternative starch media source
}

\author{
Eliandra de Freitas Sia', Joelma Marcon², Danice Mazzer Luvizotto², Maria Carolina Quecine ${ }^{2 *}$, Sarina Tsui², \\ José Odair Pereira', Aline Aparecida Pizzirani-Kleiner² and João Lúcio Azevedo ${ }^{1,2}$
}

\begin{abstract}
Endophytic fungi live inside plants, apparently do not cause any harm to their hosts and may play important roles in defense and growth promotion. Fungal growth is a routine practice at microbiological laboratories, and the Potato Dextrose Agar (PDA) is the most frequently used medium because it is a rich source of starch. However, the production of potatoes in some regions of the world can be costly. Aiming the development of a new medium source to tropical countries, in the present study, we used leaves from the guarana (a tropical plant from the Amazon region) and the olive (which grows in subtropical and temperate regions) to isolate endophytic fungi using PDA and Manihot Dextrose Agar (MDA). Cassava (Manihot esculenta) was evaluated as a substitute starch source. For guarana, the endophytic incidence (EI) was $90 \%$ and $98 \%$ on PDA and MDA media, respectively, and $65 \%$ and $70 \%$ for olive, respectively. The fungal isolates were sequenced using the ITS- rDNA region. The fungal identification demonstrated that the isolates varied according to the host plant and media source. In the guarana plant, 13 fungal genera were found using MDA and six were found using PDA. In the olive plant, six genera were obtained using PDA and 4 were obtained using MDA. The multivariate analysis results demonstrated the highest fungal diversity from guarana when using MDA medium. Interestingly, some genera were isolated from one specific host or in one specific media, suggesting the importance of these two factors in fungal isolation specificity. Thus, this study indicated that cassava is a feasible starch source that could serve as a potential alternative medium to potato medium.
\end{abstract}

Keywords: Olive; Guarana; Potato; Cassava; Manihot esculenta

\section{Background}

Endophytic fungi are known to live inside plants during parts of their life cycle and apparently do not cause any harm to their hosts. They have been found in all plant hosts so far examined and may play important roles in helping their hosts producing plant growth hormones, enzymes, and siderophores, and may act against plant diseases and insect pests (Azevedo et al. 2000; Azevedo and Araújo 2007; Vega et al. 2008; Suryanarayanan et al. 2012). The study of endophytic fungi is relevant because

\footnotetext{
* Correspondence: mquecine@usp.br

2Escola Superior de Agricultura "Luiz de Queiroz", Department of Genetics, University of São Paulo, Av. Pádua Dias 11, PO BOX 83, 13400-970 Piracicaba, SP, Brazil

Full list of author information is available at the end of the article
}

these fungi may also be used for the production of secondary metabolites and could serve as vectors for the introduction of genes that can confer pest resistance and that could express other important traits (Stierle et al. 1993; Strobel 2003; Lacava et al. 2010).

Most endophytic fungi were first studied in plants from temperate climates. These fungi have also recently been isolated from many tropical hosts. Most study results indicate that endophytes from tropical hosts constitute a species-rich ecological assemblage of fungi (Arnold et al. 2000; Arnold and Lutzoni 2007; Rungjindamai et al. 2008; Tejesvi et al. 2009; Huang et al. 2009; Rocha et al. 2011), though this is not a general trend (Suryanarayanan et al. 2011).

\section{里}

(c) 2013 Sia et al.; licensee Springer. This is an open access article distributed under the terms of the Creative Commons Attribution License (http://creativecommons.org/licenses/by/2.0), which permits unrestricted use, distribution, and reproduction in any medium, provided the original work is properly cited. 
A better understanding of fungal diversity may prove crucial in fungi utility and cultivation. However, fungi isolation in pure cultures has been limited. Of the estimated 1.5 million species that are thought to exist, less than $5 \%$ have been successfully isolated into pure cultures (Hawksworth 2001; O'Brien et al. 2005). Limitations in cultivation methods are thought to include the following: fast-growing fungal species outcompeting slower growing species; many fungi are not adapted to grow and sporulate in artificial culture media (Taylor et al. 2000; O'Brien et al. 2005). The development of a high-throughput, dilutionto-extinction approach has been developed for fungi that significantly increased the assessment of the diversity of cultured fungi (Collado et al. 2007). Novel approaches to culturing fungi that utilize low levels of nutrients or simulated natural environments have not yet been adopted, and the development of new media sources represents an important way for future research (Ferrari et al. 2011).

Thus, in the present study, we compared the abundance and diversity of endophytic fungi that were isolated from two tree species. The first species, Paullinia cupana, is a tropical plant that originated from the Brazilian Amazon forest. Its "guarana" fruits are primarily used to produce soft drinks, and it has different medicinal properties (Freitas et al. 2007). The second host used in this study was the olive plant, Olea europaea, which originated in temperate and subtropical regions and was introduced to the south and southwest of Brazil centuries ago; its fruits are used in natura and to produce olive oil (Muzzalupo et al. 2009). The primary focus of our study was that the endophytic fungi were isolated using two distinct fungal culture media: Potato Dextrose Agar (PDA), which is largely used in mycological laboratories and is derived from potato starch (Solanum tuberosum) and a recently introduced medium called Manihot Dextrose Agar (MDA) with Manihot, also called cassava or yuca (Manihiot esculenta) as an alternative source of starch (Sia 2012). M. esculenta is a tropical plant with high commercial importance to Brazil, Africa and other parts of the world. It is widely cultivated and could potentially be used to substitute PDA medium in tropical countries where cassava is cheaply cultivated. Our data strong suggest, by the increased number of isolates and the diversity of endophytic fungal communities using MDA that this medium is a great alternative to researchers access the immense unknown plant-associated fungal diversity.

\section{Results}

\section{Fungal isolation and diversity}

Both PDA and MDA media were used to isolate fungi from both the guarana and olive plants. For guarana, the EI were $90 \%$ and $98 \%$ using PDA and MDA, respectively. For the olive plant, the EI were $65 \%$ and $70 \%$ using PDA and MDA, respectively.
Sixty-one fungal isolates were obtained from guarana: 28 on PDA and 33 on MDA. Fifty-three isolates were obtained from olive: 26 on PDA and 27 on MDA. These isolates were sequenced using the ITS-rDNA region. All of the isolates were identified at the genera level and a larger amount of fungal genera was obtained from guarana than from olive (Table 1). Some genera in the endophytic fungal communities were isolated from a single host or on only a single medium. This shows the effect that these two factors have on fungal isolation specificity. The Aspergillus genus was isolated from both hosts only on MDA; a larger amount of isolates identified as Diaporthe/Phomopis were found using both hosts and both media.

In guarana, only six genera were identified using PDA and 13 genera were identified using MDA; from the olive fungal community, six genera were isolated using PDA and 4 genera using MDA. These data show that the

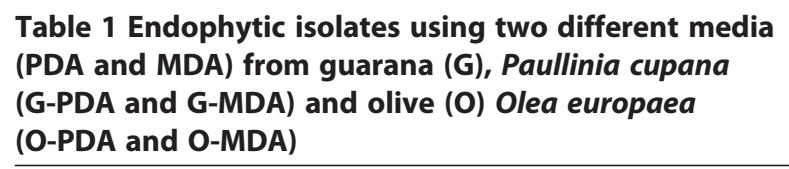

\begin{tabular}{|c|c|c|c|c|}
\hline \multirow[t]{2}{*}{ Genera } & \multicolumn{4}{|c|}{ Isolates } \\
\hline & G-PDA & G-MDA & O-PDA & O-MDA \\
\hline Aspergillus & 0 & 1 & 0 & 1 \\
\hline Bionectria & 0 & 1 & 0 & 0 \\
\hline Botrysphaeria & 1 & 2 & 0 & 0 \\
\hline Cladosporium & 0 & 2 & 0 & 0 \\
\hline Cochliobolus & 0 & 2 & 0 & 0 \\
\hline Colletotrichum & 4 & 3 & 1 & 2 \\
\hline Coniosporium & 1 & 2 & 0 & 0 \\
\hline Daldinnia & 0 & 0 & 1 & 0 \\
\hline Diaporthe Phomopsis & 12 & 8 & 20 & 22 \\
\hline Guignardia & 0 & 6 & 1 & 0 \\
\hline Nigrospora & 0 & 0 & 1 & 0 \\
\hline Pestalotiopsis & 0 & 3 & 0 & 0 \\
\hline Phanerochaete & 0 & 1 & 0 & 0 \\
\hline Pleosporales & 0 & 1 & 0 & 0 \\
\hline Sordariomycetes & 2 & 0 & 0 & 0 \\
\hline Xylaria & 8 & 1 & 2 & 2 \\
\hline \multicolumn{5}{|l|}{ Diversity parameters $^{a}$} \\
\hline S & 6 & 13 & 6 & 4 \\
\hline $\mathbf{N}$ & 28 & 33 & 26 & 27 \\
\hline D & 1.50 & 3.40 & 1.53 & 0.91 \\
\hline H'(loge) & 1.43 & 2.29 & 0.90 & 0.67 \\
\hline 1-Lambda' & 0.73 & 0.89 & 0.41 & 0.34 \\
\hline
\end{tabular}

${ }^{a}$ Diversity parameters: S-total taxon, $\mathrm{N}$-total individuals, D-species richness (Margalef), H"(loge)-Shannon and 1-lambda'-Simpson diversity indexes of endophytic fungal communities that were isolated from guarana $(G)$ and olive plants $(\mathrm{O})$ using both BDA and MDA media. 
greatest diversity was found when the guarana tree and MDA were used. Both the Shannon $\left(\mathrm{H}^{\prime \prime} \log _{\mathrm{e}}\right)$ and Simpson (1-lambda') diversity indices were highest in G-MDA (Table 1).

We used the PAST software to compare the diversity indices ( $t$ test) for PDA and MDA to obtain significant values $(p<0.05)$ for $\mathrm{PDA}$ and MDA separation when isolating fungi from guarana. The significant values for the media types did not differ when isolating fungi from the olive plant. Guarana and olive have distinct communities that are independent of the media source (Table 2).

Guarana has a more diverse fungal community that is better assessed when MDA is used as media source. We observed the separation of some isolates within each genus, and this separation was dependent on the host. A media-influenced separation of isolates was not observed. However, some other notable observations were made. The Xylaria fungi were obtained from both plant and media, but from guarana G-MDA32 did not cluster with the other Xylaria when using PDA (Figure 1). A similar result was found among the Botrysphaeria fungi. The isolate G-PDA23 did not cluster with G-MDA25 or GMDA27, suggesting that the media type influenced the selection of isolates within a genus. The isolates from olive did not differ with the media source (Figure 1b).

\section{PCA and similarity analysis}

DCA analysis of the species distribution revealed gradient lengths of 1.592 in size, which showed a linear distribution of data, justifying the use of redundancy analysis of these isolated fungal communities. The host was the most important factor affecting the composition of the fungal communities in both media, as can be observed in Figure $2 \mathrm{a}$ (its vector is most closely correlated with the first axis of the ordination diagram). This effect was

\section{Table 2 Diversity $t$ test on endophytic fungi that were isolated from guarana and olive plants using PDA and MDA media}

\begin{tabular}{lccc}
\hline PDA vs MDA media & & & \\
\hline & Variance & $\boldsymbol{p}$ & $\mathbf{t}$ \\
\hline Whole sample & 0.49 & $0.003^{* *}$ & -3.03 \\
Guarana & 0.09 & $0.0017^{* *}$ & -3.27 \\
Olive & 0.02 & 0.29 (ns) & -1.06 \\
Guarana vs Olive host & & & \\
& Variance & $\boldsymbol{p}$ & $\mathbf{t}$ \\
Whole sample & 0.21 & $7.3 \mathrm{E}-06^{* *}$ & 5.23 \\
PDA & 0.07 & $0.035^{*}$ & 2.169 \\
MDA & 0.198 & $0.00011^{* *}$ & 4.14 \\
\hline
\end{tabular}

ns-non-significant.

*Differ statistically with $P>0.05$.

**Differ statistically with $P>0.01$. significant, and the Lambda 1 values were 0.67 and 0.13 for the host and media, respectively (Figure 2b). Using clustering analysis, we observed a clear grouping of the isolates from olive (Figure 3), which shows a higher similarity between the fungal communities in a host than those in a media.

\section{Discussion}

The present work reported the isolation, identification and characterization of cultured endophytic fungi from leaves of two climatically distinct plants (guarana and olive) using two types of starch source media (PDA and MDA).

Independently of the host plant, the MDA medium showed to be an alternative medium. The influence of the media on fungal growth is commonly described in laboratory procedures. Silva and Teixeira (2012) characterized Fusarium solani isolates from cassava roots under different media and light conditions and observed a better mycelial fungal growth on PSA (Potato Sucrose Agar). The MDA medium has also shown better mycelia growth and poorer spore formation compared with those in the PDA medium (Sia 2012). This could result in the increased isolation of some fungal species in MDA compared with PDA.

Over recent decades, potatoes have been a more common starch source for use in fungal growth-promoting media due to their complex carbohydrates, which improve the reproduction of mitosporic fungi (Lukens 1963; Strandberg 1987). However, new alternatives have been developed. Fungal isolation using the MDA medium demonstrated its viability as an alternative due to its ability to support a greater diversity and number of isolates of fungal communities (especially from a tropical host).

The MDA medium presents economic advantages over potatoes in tropical countries because cassava is cheaply and easily found in these countries. Moreover, most potato plantations are submitted to agrochemical treatment, which often results in fungal growth inhibition, whereas a traditional cassava plantation is generally free of agrochemicals.

Coniosporium, Phaerochaete and Biocnectria were only isolated using MDA and guarana. The isolation of these genera is not common in tropical plants. Phanerochaete was recently isolated from the plant Andrographis paniculata (Biji et al. 2011), and Bionectria was recently isolated from leaf tissues of Sonneratia caseolaris (Ebrahim et al. 2012). All of these genera (and others found in guarana) have interesting characteristics that are otherwise never related with tropical plants. For example, some species of the genus Coniosporium occur primarily on dead or living plant material or as a biodegradative fungus on aging monuments (Sert and Sterflinger 2010). The white rot fungi, genus Phanerochaete, have been reported to be highly lignolytic and cellulolytic. The genus Bionectria 


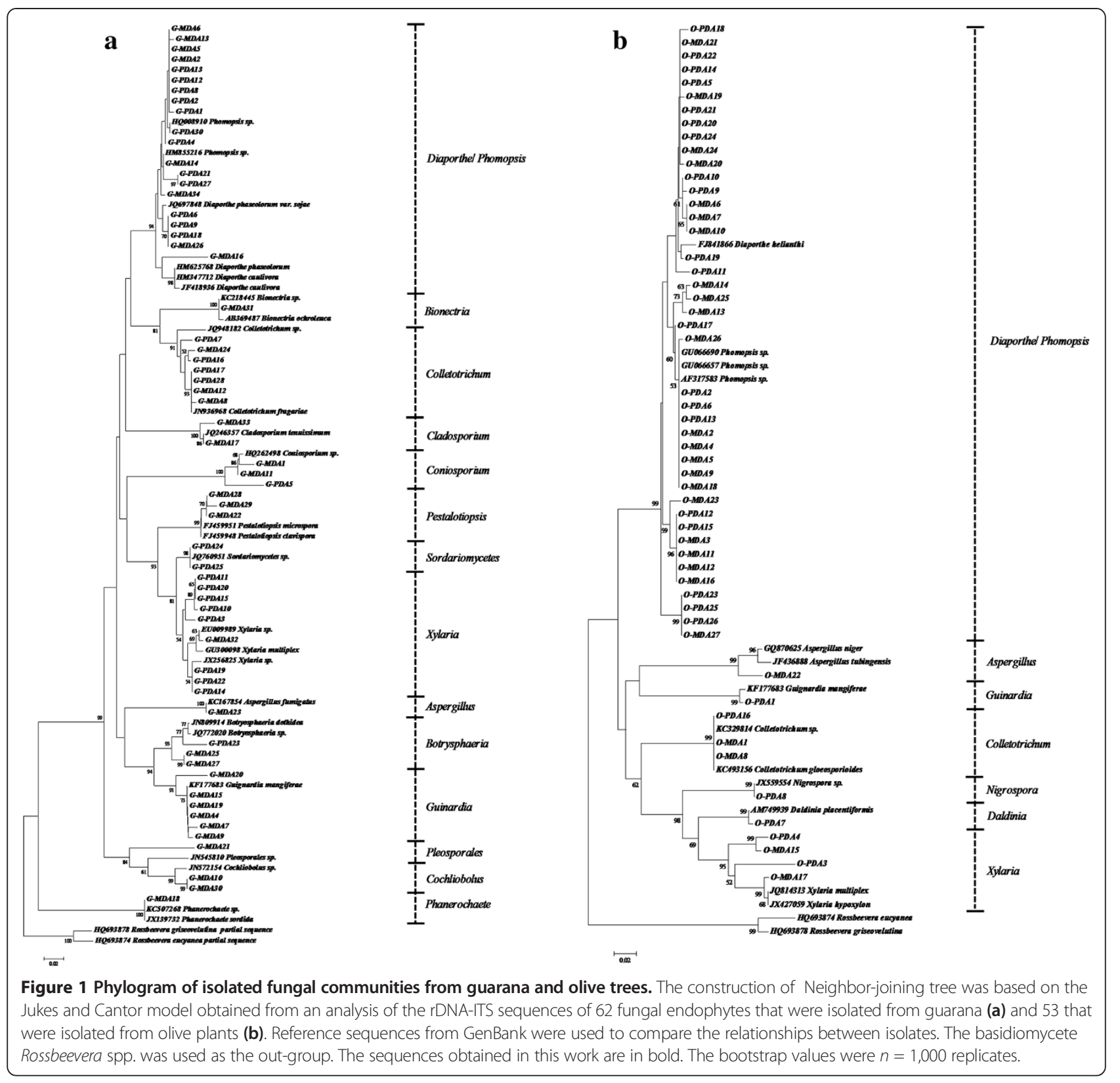

is important in decomposing plant debris and has other useful properties (Rossman 1996). Thus, these fungi may play important roles in decomposing plant material that later provides nutrition to their plant hosts in the Amazon.

Colletotrichum and Diaporthe/Phomopsis were isolated in both plants and both media. Colletotrichum are often symptomatic pathogens that have been isolated from numerous plant species. However, they can also be asymptomatic endophytes. Colletotrichum spp. can cause anthracnose in olive and guarana trees, which results in severe production loss (Duarte et al. 1995; Talhinhas et al. 2005). This genus is also a common tropical fruit plant pathogen in avocado, banana, citrus, mango, papaya, passion fruit, guava and cashew cultivation (Afanador-Kafuri et al. 2003; Figueirêdo et al. 2012). However, the leaves sampled in present study were healthy and without anthracnose symptoms. Colletotrichum is known for its production of the anticancer drug taxol (Gangadevi and Muthumary 2008). The medicinally and industrially important extra cellular lipase (Balaji and Ebenezer 2008), an antimicrobial metabolite (colletotric acid (Zou et al. 2000)) and colletotric acid (an 11/-hydroxysteroid dehydrogenase type $1(11 \beta$ HSD1) inhibitor (Aoyagi et al. 2008)) were also isolated from these fungi genera. The cosmopolitan lifestyle of this interesting fungal group is likely a consequence of 


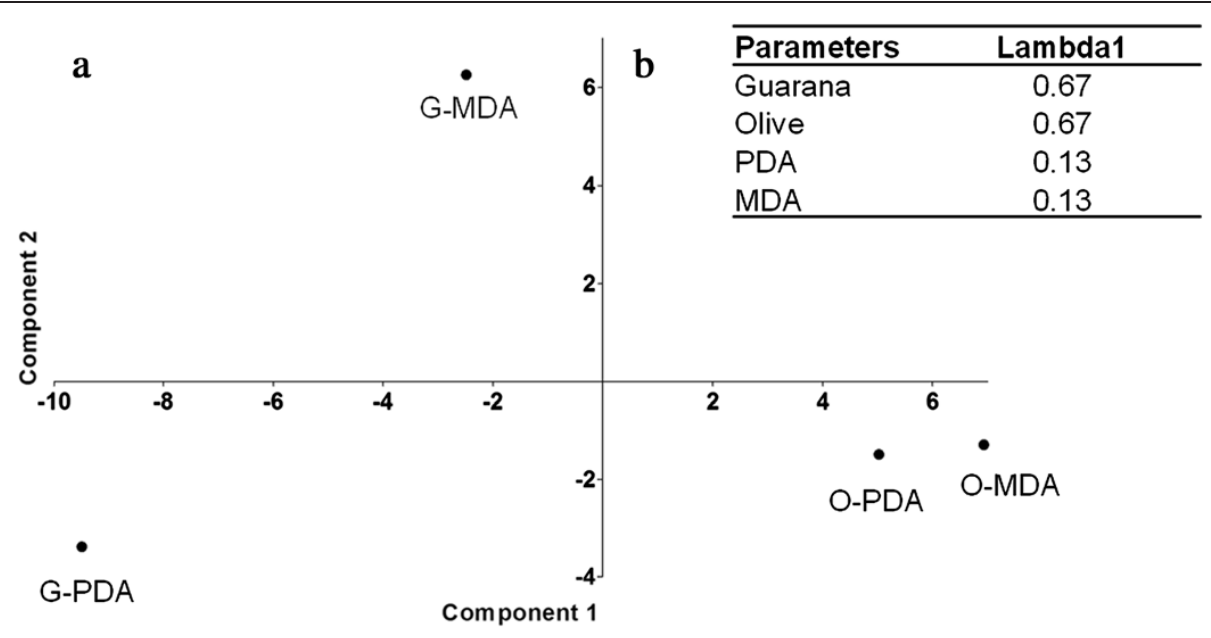

Figure 2 Multivariate analysis of the isolated fungal from guarana (G) and olive plants (O) on MDA and PDA media. (a) Principal components analysis (PCA) (b) Statistical parameters calculated using multivariate analyses with inclusion of a Monte Carlo permutation test. The values for Lambda 1 indicate the amount of variance that is explained by each parameter.

the high morphology and genetic variation that happens in the species of this genus (Sutton 1992).

Interestingly, a large amount of endophytic isolates found primarily in olive plants were identified as Diaporthe/ Phomopsis, suggesting that this genus is a dominant member of the guarana and olive plant endophytic community. Silva et al. (2005) studied the bioactive metabolites that are produced by endophytic fungi in the cassia tree (Cassia spectabilis, family Leguminosae) and observed that the genus Phomopsis potentially produces many biologically antifungal metabolites and especially those against the phytopathogenic fungi Cladosporium sphaerospermum and C. cladosporioides. Nithya and Muthumary (2010) verified that the genus Phomopsis has a strong antibacterial activity and is a rich source of secondary metabolites. Phomopsis spp. were also isolated from Amazonian toxic plants (Souza et al. 2004), and further investigation is needed regarding its role as an endophyte of tropical and temperate host trees.

PDA and MDA had the same performance regarding olive fungi isolation but PDA presented less fungi genera diversity compared to MDA when used with guarana. To study the composition of the endophytic community of olive plants (O. europaea L.) from two sites in Sicily

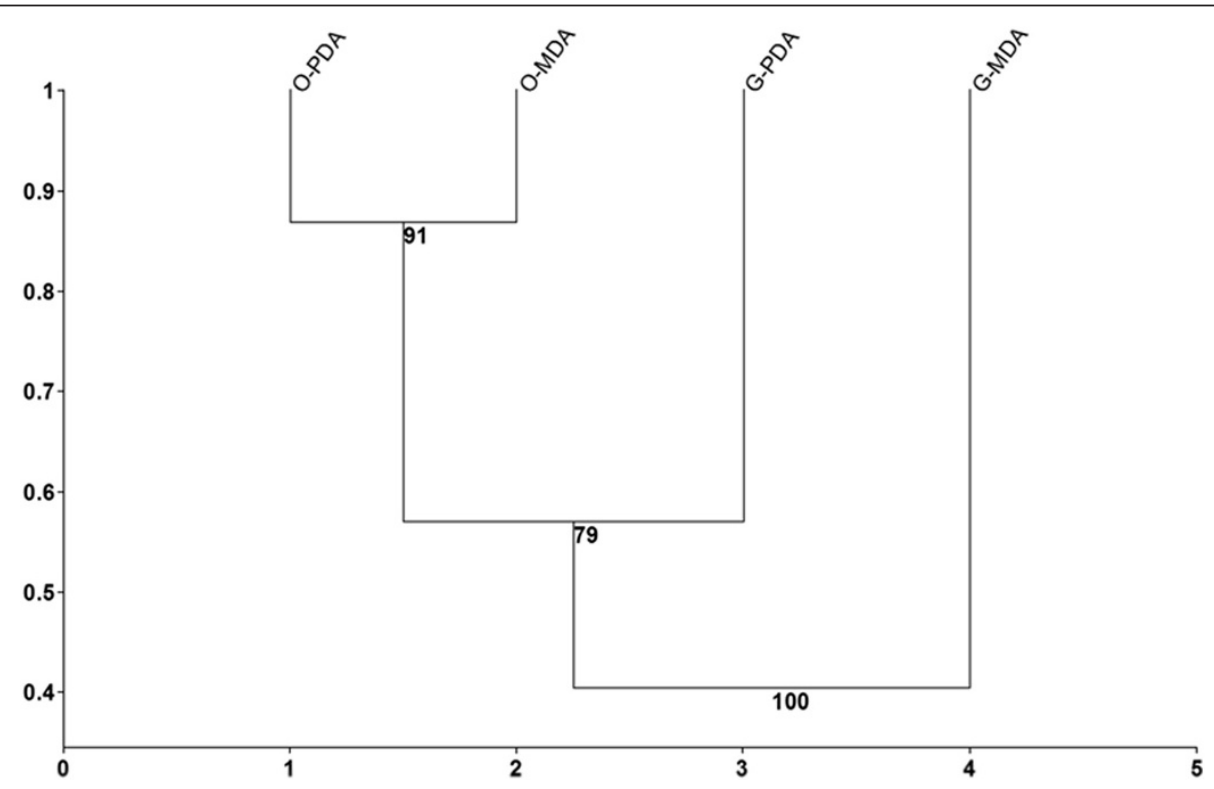

Figure 3 Clustering of the similarity of endophytic fungal communities from guarana (G) and olive plants (O) isolated using PDA and MDA. The bootstraps are the means of 1,000 repetitions. 
(Italy), Ferraro et al. (2008) observed that the number of fungal isolates differed between the sampled sites, using the malt extract agar medium (MEA), the prevailing fungal genera were Alternaria, Cladosporium, Diplodia, Phoma, Septoria and Stemphylium. When comparing the isolates from the two sites, the authors observed that the endophytic assemblages in olive trees had a similar composition at both of the sampled sites. However, none of the genera described by the authors were identified in the present study. The endophytic fungal species detected in plants may be influenced by many factors including the type of tissue sampled, when the plant was assayed, and perhaps the climate and location in which they grew (Impullitti and Malvick 2013), as well as the media used to isolate species. However, the influence of the media may be dependent on the accessed host. Using similarity data, we observed strong clustering between the PDA and MDA fungal communities that were isolated from olive plants. The similarity between separate guarana fungal communities that were isolated on either PDA or MDA was not significant. This suggests that media exerts more influence on fungal selection for diverse fungal communities such as those in tropical plants.

Although the early endophytic fungi studies were performed on temperate climate plant species, some studies (Arnold et al. 2000; Frohlich and Hyde 1999; Lodge et al. 1996) demonstrated that tropical plant species are host to a greater fungal biodiversity. Our data proved that guarana and olive plants presented distinct fungal communities. However, few studies have quantified the endophyte colonization patterns in tropical plants (Arnold et al. 2000). Most of the results thus far indicate that tropical endophytes themselves may be hyper-diverse; therefore, tropical host endophytes constitute a species-rich ecological assemblage of fungi. The results from other studies corroborate our hypothesis and demonstrate that using alternative media should improve the investigation and elucidation of these organisms.

The clustering of PDA and MDA isolated endophytic fungal communities from guarana and olive plants showed a higher fungal community similarity according to host than according to medium. The present data demonstrated that most of the variance in fungal species was explained by the host. However, the media likely influence the selection some isolated species. According to Arnold et al. (2000), tropical forests contribute substantially to fungal diversity, and considering statements by Carnaúba et al. (2007), the media composition is a determining factor in fungal growth.

\section{Conclusions}

The results of the present study demonstrated the feasible use of MDA as an alternative medium source to fungal growth. The important role of the media in fungal isolation from two common trees in tropical and subtropical climates was also proved. The MDA media showed more diverse results that demonstrate its potential as an alternative starch source for laboratorial fungal growth. The implementation of this media for the isolation of endophytic fungi should improve the number of isolates and increase access to a greater diversity of the fungal community.

\section{Methods}

\section{Culture media}

Two culture media were used: Potato Dextrose Agar (PDA) was prepared in our laboratory, and consisted of potato extract (200 g), dextrose (20 g), agar (15 g), and distilled water to a final volume of one liter with a $\mathrm{pH}$ of 6.5 . Manihot Dextrose Agar (MDA) was prepared using the same method as PDA but with $200 \mathrm{~g}$ of cassava instead of potato. To prepare the potato and cassava extracts, $200 \mathrm{~g}$ of each plant tuber was cut into pieces and heated in distilled water for $30 \mathrm{~min}$. The infusion was filtered, dextrose was added and the $\mathrm{pH}$ was adjusted to 6.5 . After agar addition, the media were autoclaved for $15 \mathrm{~min}$ at $121^{\circ} \mathrm{C}$ (Sia 2012).

\section{Fungal isolation}

Endophytic fungi were isolated from two independent experiments, two plant species: olive (O. europaea), which is a common plant in temperate and subtropical areas, and guarana (P. cupana), which is a tropical plant native to the Amazon region. A random sample from each tree consisting of approximately ten healthy leaves was taken for $P$. cupana from the Brazilian Amazon town of Maués (03 $23^{\prime}$ $\left.01^{\prime \prime} \mathrm{S}, 57^{\circ} 43^{\prime} 07^{\prime \prime} \mathrm{W}\right)$ and for O. europaea from the campus of the Agriculture School, University of São Paulo, Piracicaba, Brazil $\left(22^{\circ} 43^{\prime} 30^{\prime \prime} \mathrm{S}, 47^{\circ} 38^{\prime} 51^{\prime \prime} \mathrm{W}\right)$. After removal, the leaves were placed in plastic bags and transported to the laboratory. They were used within $24 \mathrm{~h}$ of their removal. All of the leaves were washed with running tap water. The plant tissues were rinsed with $70 \%$ ethanol for $1 \mathrm{~min}$ and their surfaces were disinfected with a sodium hypochlorite solution $\left(3 \%\right.$ available $\left.\mathrm{Cl}^{-}\right)$for $3 \mathrm{~min}$. They were again rinsed once for $30 \mathrm{~s}$ in $70 \%$ ethanol and then rinsed twice in sterile distilled water according to Araújo et al. (2001). The efficiency of the disinfection process was checked by plating aliquots of the sterile distilled water that was used in the final rinse on Potato Dextrose Agar (PDA) and Manihiot Dextrose Agar (MDA). After surface disinfection, each leaf was cut into square fragments $(4-6 \mathrm{~mm})$ that were placed onto PDA or MDA that contained tetracycline $(50 \mu \mathrm{g} / \mathrm{mL})$ and streptomycin $(50 \mu \mathrm{g} / \mathrm{mL})$ to suppress bacteria growth. From each experiment, for each plant species, 17 plates from each media were used. A total of 102 leaf fragments were used 
for each plant host (six fragments per Petri dish). After 30 days of incubation at $28^{\circ} \mathrm{C}$, the hyphal tips of each morphologically different mycelium that emerged from a leaf fragment were subcultured and transferred to PDA or MDA. These tips were purified and then transferred to slants for later identification. The preservation of the isolates was performed according to the Castellani method (Castellani 1967). The endophyte incidence (EI) was calculated as: the percentage of pieces that showed fungal growth/total number of pieces that were screened $\times 100$.

\section{Molecular identification}

The DNA extraction was performed on 150 purified fungal strains according to the method used by Raeder and Broda (1985). The amplification of ITS1-5.8S-ITS2 rDNA was performed using the primers ITS1 (5'TCCGTAGGTGA ACCTGCGG'3) and ITS4R (5'TCCTCCGCTTATTGAT ATGC'3) in a Peltier Thermal Cycler PTC200 (MJ Research Inc, Watertown, MA). The PCR mix contained 3 ng of template DNA, $0.4 \mu \mathrm{M}$ of each primer, $3.7 \mathrm{mM}$ of $\mathrm{MgCl}_{2}, 250 \mu \mathrm{M}$ of each dNTP, $2 \mathrm{U}$ of Taq DNA polymerase (Invitrogen, Brazil), $50 \mathrm{mM}$ of Tris- $\mathrm{HCl}(\mathrm{pH} 8.4)$, and $20 \mathrm{mM}$ of $\mathrm{KCl}$ to achieve a $50 \mu \mathrm{L}$ final volume. The PCR consisted of 35 cycles (denaturing for $30 \mathrm{~s}$ at $94^{\circ} \mathrm{C}$, primer annealing for $30 \mathrm{~s}$ at $55^{\circ} \mathrm{C}$ and extension for $30 \mathrm{~s}$ at $72^{\circ} \mathrm{C}$ ). Negative controls containing all reagents except for the genomic DNA were prepared in each PCR reaction. The PCR product was analyzed using electrophoresis on $1.0 \%$ $\mathrm{w} / \mathrm{v}$ agarose gels, stained with ethidium bromide and visualized under UV light.

The amplified fragments were purified using polyetilene glicol (Sambrook and Russell 2001) and sequenced by the Human Genome Research Center, Institute of Biosciences, University of São Paulo, São Paulo, Brazil with the ABI 3730 DNA Analyzer (Applied Biosystems) according to the manufacturer's instructions.

\section{Sequence assembly and alignment}

Consensus sequences were manually aligned using the MEGA v5.1 software (Tamura et al. 2011) and BioEdit 7.0 (Hall 1999) to insert gaps. rDNA-ITS sequences were aligned on the basis of similarity by means of the sequence alignment software CLUSTAL-W 1.7 (Thompson et al. 1994). The identification of sequences was realized using blastn and the nucleotide collection $(\mathrm{nr} / \mathrm{nt})$ database (http://www.ncbi.nlm.nih.gov/blast/).

The neighbor-joining analyses were conducted using Megav5.1 with the branch support values obtained after 1,000 heuristic searches for pseudo replicates. The sequences presented in this study (a total of 114 sequences) were submitted to GenBank (accession numbers JX944069JX944183). The many diversity parameter indices were: $\mathrm{S}$-total profile, $\mathrm{N}$ - profile value, $\mathrm{d}$-species richness
(Margalef), and H" (loge) - Shannon and 1-lambda'Simpson diversities were obtained using 'Primer 6' (Plymouth Marine, Primer, United Kingdom).

\section{Data analysis}

The correlations between individual isolates and environmental variables (plant species and media used) were determined using multivariate analysis with Canoco for Windows 4.5 software (Biometris, Wageningen, The Netherlands) and following the same procedures as previously described (Andreote et al. 2009; Ramete 2007; Ter Braak and Šmilauer 2002). Briefly, a detrended correspondence analysis (DCA) was performed to calculate the gradient distribution of the genera in all of the evaluated treatments. In the case of normal distribution in fungal community identification (gradient in the first axis $<4.0$ ), the data were analyzed using Redundancy Analysis (RDA). For statistical analyses of correlations between genera and variable factors (host plant and media), a Monte Carlo permutation test was performed and was based on 499 unrestricted permutations. In addition to the P-values, the values of Lambda 1 were obtained to quantify the amount of variance that could be explained by each variable factor. The data were also analyzed using principal component analysis (PCA). The axis values showed the percentage variance of each accessed fungal community.

We also performed similarity clustering using the PAST program (Hammer et al. 2001) to prove that there were significant differences between the communities (Clarke and Ainsworth 1993). The Bray-Curtis model was adapted to the present data.

\section{Competing interests}

The authors declare that they have no competing interests.

\section{Authors' contributions}

The work presented here was carried out in collaboration between all authors. EFS, JM, DML, and JLA defined the research theme. MCQ and ST were primarily involved in searching, statistical analysis, compilation and verification and interpretation of data, and wrote the paper. JOP, AAPK assisted with manuscript preparation. All authors have contributed to, seen and approved the manuscript.

\section{Acknowledgments}

This work was supported by a grant from the Foundation for Research Assistance, São Paulo State and Amazon State, Brazil (grant n. 2009/53376-2) and by the National Council for Scientific and Technological Development (CNPq). We thank FAPESP for the M.C.Q. (grant no. 2010/50445-0), J.M. (grant no. 2011/18740-5) and S.T. (grant no. 2010/15192-4) and CNPq for E.F.S. and D.M.L. fellowships.

\section{Author details}

${ }^{1}$ Universidade Federal do Amazonas-UFAM, Avenida Rodrigo Otávio Ramos 3000,Colorado I, Manaus 69.077-000, AM, Brazil. ²Escola Superior de Agricultura "Luiz de Queiroz", Department of Genetics, University of São Paulo, Av. Pádua Dias 11, PO BOX 83, 13400-970 Piracicaba, SP, Brazil.

Received: 17 July 2013 Accepted: 28 October 2013

Published: 30 October 2013 


\section{References}

Afanador-Kafuri L, Minz D, Maymon M, Freeman S (2003) Characterization of colletotrichum isolates from tamarillo, passiflora, and mango in Colombia and identification of a unique species from the genus. Phytopathology 9:579-587, doi:10.1094/PHYTO.2003.93.5.579

Andreote FD, Azevedo JL, Araujo WL (2009) Assessing the diversity of bacterial communities associated with plants. Braz J Microbiol 40:417-432, doi:10.1590/S1517-83822009000300001

Aoyagi A, Ito-Kobayashi M, Ono Y, Furukawa Y, Takahashi M, Muramatsu Y, Umetani M, Takatsu T (2008) Colletoic acid, a novel $11 \beta$-hydroxysteroid dehydrogenase type 1 inhibitor from Colletotrichum gloeosporioides SANK 21404. J Antibiot 61:136-141, doi:10.1038/ja.2008.122

Araújo WL, Maccheroni Junior W, Aguilar-vildoso Cl, Barroso PAV, Saridakis HO, Azevedo JL (2001) Variability and interactions between endophytic bacteria and fungi isolated from leaf tissues of citrus rootstocks. Can J Microbiol 47:229-236, doi:10.1139/cjm-47-3-229

Arnold AE, Lutzoni F (2007) Diversity and host range of foliar fungal endophytes: are tropical leaves biodiversity hotspots? Ecology 88:541-549, doi:10.3410/ f.1087244.540250

Arnold AE, Maynard Z, Coley PD, Kursar TA (2000) Are tropical fungal endophytes hyperdiverse? Ecol Lett 3:267-274, doi:10.1046/j.1461-0248.2000.00159.x

Azevedo JL, Araújo WL (2007) Diversity and applications of endophytic fungi isolated from tropical plants. In: Ganguli BN, Deshmukh SK (eds) Fungi: Multifaceted Microbes. Anamaya Publishers, New Delhi, pp 189-207

Azevedo JL, Maccheroni Junior W, Pereira JO, Araujo WL (2000) Endophytic microorganisms: a review on insect control and recent advances on tropical plants. Electron J Biotechnol 3:40-65, doi:10.2225/vol3-issue1-fulltext-4

Balaji V, Ebenezer P (2008) Optimization of extracellular lipase production in Colletotrichum gloeosporioides by solid state fermentation. Indian J Sci Technol 7:1-8

Biji CP, Sudheendrakumar W, Shadna P (2011) Fungal endophytes Phlebiopsis gigantea (Fr.) Julich and Phanerochaete sordida (P.Karst) J. Erikss. and Ryvarden: New aspirants in biopesticide scenario. J Biol Control 25:114-117

Carnaúba JP, Sobral MF, Amorim EP (2007) Avaliação de diferentes meios de cultura na esporulação de Scytalidium lignicola. Summa Phytopathol 33:199-200, doi:10.1590/S0100-54052007000200018

Castellani A (1967) Maintenance and cultivation of common pathogenic fungal in sterile distilled water for the researches. J Trop Med Hyg 70:181-184

Clarke KR, Ainsworth M (1993) A method of linking multivariate community structure to environmental variables. Mar Ecol Prog Ser 92:205-219, doi:10.3354/meps092205

Collado J, Platas G, Paulus B, Bills GF (2007) High-throughput culturing of fungi from plant litter by a dilution-to-extinction technique. FEMS Microbiol Ecol 60:521-533, doi:10.1111/j.1574-6941.2007.00294.x

Duarte MLR, Albuquerque FC, Correa MPF (1995) Physiological and morphological changes in Colletotrichum guaranicola isolates. Fitopatol Bras 20:141-144

Ebrahim W, Kjer J, El Amrani M, Wray V, Lin W, Ebel R, Lai D, Proksch P (2012) Pullularins $E$ and $F$, two new peptides from the endophytic fungus Bionectria ochroleuca isolated from the mangrove plant Sonneratia casoelaris. Mar Drugs 10:1081-1091, doi:10.3390/md10051081

Ferrari BC, Zhang C, van Dorst J (2011) Recovering greater fungal diversity from pristine and diesel fuel contaminated sub-Antarctic soil through cultivation using both a high and a low nutrient media approach. Front Microbiol 2:217, doi:10.3389/fmicb.2011.00217

Ferraro V, Conigliaro G, Torta L, Burruano S, Moschetti G (2008) Preliminary investigation on the endophytic communities in Olea europaea in Sicily. In: Cross J, Brown M, Fitzgerald J, Fountain M, Yohalem J (eds) IOBC Working Groups "Integrated fruit protection in fruit crops". Proceedings of the 7th International Conference on Integrated Fruit Production, Avignon., pp 459-463

Figueirêdo LC, Figueirêdo GS, Quecine MC, Cavalcanti FCN, Santos AC, Costa AF, Oliveira NT, Azevedo JL (2012) Genetic and pathogenic diversity of Colletotrichum gloeosporioides, the causal agent of cashew anthracnose. Indian J Fund Appl Life Sci 2:250-259

Freitas DV, Carvalho CR, Filho FJ, Astolfi-Filho S (2007) Karyotype with 210 chromosomes in guaraná (Paullinia cupana 'Sorbilis'). J Plant Res 120:399-404, doi:10.1007/s10265-007-0073-4

Frohlich J, Hyde KD (1999) Biodiversity of palm fungi in the tropics: are global fungal diversity estimates realistic? Biodivers Conserv 8:977-1004, doi:10.1023/A:1008895913857
Gangadevi V, Muthumary J (2008) Isolation of Colletotrichum gloeosporioides, a novel endophytic Taxol-producing fungus from the leaves of a medicinal plant, Justicia gendarussa. Mycol Balc 5:1-4

Hall TA (1999) Bio-Edit: a user-friendly biological sequence alignment editor and analysis program for Windows 95/98/NT. Nucleic Acids Symp Ser 41:95-98

Hammer $\varnothing$, Harper DAT, Ryan PD (2001) PAST: paleontological statistics software package for education and data analysis. Paleontol Electronica 4:1-9

Hawksworth DL (2001) The magnitude of fungal diversity: the 1.5 million species estimate revisited. Mycol Res 105:1422-1432, doi:10.1017/ S0953756201004725

Huang WY, Cai YZ, Surveswaran S, Hyde KD, Corke H, Sun M (2009) Molecular phylogenetic identification of endophytic fungi isolated from three Artemisia species. Fungal Divers 36:69-88

Impullitti AE, Malvick DK (2013) Fungal endophyte diversity in soybean. J Appl Microbiol, doi:10.1111/jam.12164

Lacava PT, Sebastianes FLS, Azevedo JL (2010) Fungos endofíticos: biodiversidade e aplicações biotecnológicas. In: Esposito E, Azevedo JL (eds) Fungos, uma introdução à biologia, química e biotecnologia, 2nd edn. Universidade Caxias do Sul, Rio Grande do Sul, pp 533-569

Lodge DJ, Fisher J, Sutton BC (1996) Endophytic fungi of Manikara bidentata leaves in Puerto Rico. Mycologia 88:733-738, doi:10.2307/3760967

Lukens RJ (1963) Photo-inhibition of sporulation in Alternaria solani. Am J Bot 50:721-724

Muzzalupo I, Stefanizzi F, Salimonti A, Falabella R, Perri E (2009) Microsatellite markers for identification of a group of italian olive accessions. Sci Agric 66:685-690, doi:10.1590/S0103-90162009000500014

Nithya K, Muthumary J (2010) Secondary metabolite from Phomopsis sp. isolated from Plumeria acutifolia Poiret. Recent Res Sci Tech 4:99-103

O'Brien HE, Parrent JL, Jackson JA, Moncalvo J, Vilgalys R (2005) Fungal community analysis by large-scale sequencing of environmental samples. Appl Environ Microbiol 71:5544-5550, doi:10.1128/AEM.71.9.5544-5550.2005

Raeder U, Broda P (1985) Rapid preparation of DNA from filamentous fungi. Lett Appl Microbiol 1:17-20, doi:10.1111/j.1472-765X.1985.tb01479.x

Ramete A (2007) Multivariate analyses in microbial ecology. FEMS Microbiol Ecol 62:142-160, doi:10.1111/j.1574-6941.2007.00375.x

Rocha ACS, Garcia D, Uetanabaro APT, Carneiro RTO, Araújo IS, Mattos CRR, GóesNeto A (2011) Foliar endophytic fungi from Hevea brasiliensis and their antagonism on Microcyclus ulei. Fungal Divers 47:75-84, doi:10.1007/s13225-010-0044-2

Rossman AY (1996) Morphological and moleclar perspectives on systematics of the Hypocreales. Mycologia 88:1-19

Rungjindamai N, Pinruan U, Choeyklin R, Hattori T, Jones EBG (2008) Molecular characterization of basidiomycetous endophytes isolated from leaves, rachis and petioles of the oil palm, Elaeis guineensis, in Thailand. Fungal Divers 33:139-162

Sambrook J, Russell DW (2001) Molecular Cloning: A laboratory Manual. Cold Spring Harbor, New York

Sert HB, Sterflinger K (2010) A new Coniosporium species from historical marble monuments. Mycol Prog 9:353-359, doi:10.1007/s11557-009-0643-z

Sia EF (2012) Meios de cultura alternativos para fungos utilizando diferentes substratos, especialmente de mandioca (Manihot esculenta). Federal University of Amazon, Dissertation

Silva JL, Teixeira RNV (2012) Esporulação e crescimento micelial de Fusarium solani em diferentes meios de cultura e regimes de luminosidade. Ver Agro@ambiente On-line 6:47-52

Silva GHS, Teles HL, Trevisan HC, Bolzani VS, Young MCM, Pfenning LH, Eberlin MN, Haddad R, Costa-Neto CM, Araújo AR (2005) New bioactive metabolites produced by Phomopsis cassie, an endophytic fungus in Cassia spectabilis. J Brazil Chem Soc 16:1463-1466, doi:10.1590/S0103-50532005000800029

Souza AQL, Souza ADL, Astolfi-Filho S, Belém-Pinheiro ML, Sarquis MIM, Pereira JO (2004) Antimicrobial activity of endophytic fungi isolated from amazonian toxic plants: Palicourea longiflora (aubl.) rich and Strychnos cogens bentham. Acta Amaz 34:185-195, doi:10.1590/S0044-59672004000200006

Stierle A, Strobel G, Stierle D (1993) Taxol and taxane production by Taxomyces andreanae, an endophytic fungus of Pacific yew. Science 260:214-216, doi:10.1126/science.8097061

Strandberg JO (1987) Isolation, storage, and inoculums production methods for Alternaria dauci. Phytopathology 77:1008-1012, doi:10.1094/Phyto-77-1008

Strobel GA (2003) Endophytes as sources of bioactive products. Microbes Infect 5:535-544, doi:10.1016/S1286-4579(03)00073-X 

three tropical forest types of the Western Ghats, Southern India. Biodivers Conserv 20:913-928, doi:10.1007/s10531-011-0004-5

Suryanarayanan TS, Thirunavukkarasu N, Govindarajulu MB, Gopalan V (2012) Fungal endophytes: an untapped source of biocatalysts. Fungal Divers 54:1930, doi:10.1007/s13225-012-0168-7

Sutton BC (1992) The genus Gromerella and it's anamorph Colletotrichum. In: Bailey JA, Jeger MJ (eds) Colletotrichum: biology, pathology and control. CAB International, Wallinford, pp 1-26

Talhinhas P, Sreenivasaprasad S, Neves-Martins J, Oliveira H (2005) Molecular and phenotypic analyses reveal association of diverse Colletotrichum acutatum groups and a low level of C. gloeosporioides with olive anthracnose. Appl Environ Microbiol 71:2987-2998, doi:10.1128/ AEM.71.6.2987-2998.2005

Tamura K, Peterson D, Peterson N, Stecher G, Nei M, Kumar S (2011) MEGA5: molecular evolutionary genetics analysis using maximum likelihood, evolutionary distance, and maximum parsimony methods. Mol Biol Evol 28:2731-2739, doi:10.1093/molbev/msr121

Taylor JW, Jacobson DJ, Kro- Ken S, Kasuga T, Geiser DM, Hibbett DS, Fischer MC (2000) Phylogenetic species recognition and species concepts in fungi. Fungal Genet Biol 31:21-32, doi:10.1006/fgbi.2000.1228

Tejesvi MV, Tamhankar SA, Kini KR, Rao VS, Prakash HS (2009) Phylogenetic analysis of endophytic Pestalotiopsis species from ethnopharmaceutically important medicinal trees. Fungal Divers 38:167-183, doi:10.1055/s-00291185951

Ter Braak CJF, Šmilauer P (2002) CANOCO Reference Manual and CanoDraw for Windows User's Guide: Software for Canonical Community Ordination (version 4.5). Microcomputer Power, Ithaca, New York

Thompson JD, Higgins DG, Gibson TJ (1994) CLUSTAL W: improving the sensitivity of progressive multiple sequence alignment through sequence weighting, position-specific gap penalties and weight matrix choice. Nucleic Acids Res 22:4673-4680, doi:10.1093/nar/22.22.4673

Vega FE, Posada F, Aime MC, Pava-Ripoli M, Infante F, Rehner SA (2008) Entomopathogenic fungal endophytes. Biol Control 46:72-82, doi:10.1016/j.biocontrol.2008.01.008

Zou WX, Meng JC, Lu H, Chen GX, Shi GX, Zhang TY, Tan RX (2000) Metabolites of Colletotrichum gloeosporioides, an Endophytic Fungus in Artemisia mongolica. J Nat Prod 63:1529-1530, doi:10.1021/np000204t

doi:10.1186/2193-1801-2-579

Cite this article as: Sia et al:: Endophytic fungi from the Amazonian plant Paullinia cupana and from Olea europaea isolated using cassava as an alternative starch media source. SpringerPlus 2013 2:579.

\section{Submit your manuscript to a SpringerOpen ${ }^{\odot}$ journal and benefit from:}

- Convenient online submission

- Rigorous peer review

- Immediate publication on acceptance

- Open access: articles freely available online

- High visibility within the field

- Retaining the copyright to your article

Submit your next manuscript at springeropen.com 